University of Nebraska - Lincoln

DigitalCommons@University of Nebraska - Lincoln

Biological Systems Engineering: Papers and

Publications

Biological Systems Engineering

6-1984

\title{
Model and Production Function for Irrigation Management
}

Derrel L. Martin

University of Nebraska-Lincoln, derrel.martin@unl.edu

Darrell G. Watts

University of Nebraska-Lincoln

James R. Gilley

University of Nebraska-Lincoln

Follow this and additional works at: https://digitalcommons.unl.edu/biosysengfacpub

Part of the Biological Engineering Commons

Martin, Derrel L.; Watts, Darrell G.; and Gilley, James R., "Model and Production Function for Irrigation Management" (1984). Biological Systems Engineering: Papers and Publications. 58.

https://digitalcommons.unl.edu/biosysengfacpub/58

This Article is brought to you for free and open access by the Biological Systems Engineering at DigitalCommons@University of Nebraska - Lincoln. It has been accepted for inclusion in Biological Systems Engineering: Papers and Publications by an authorized administrator of DigitalCommons@University of Nebraska Lincoln. 


\title{
Model and Production Function for Irrigation Management
}

\author{
Derrel L. Martin, ${ }^{*}$ Darrell G. Watts, ${ }^{\dagger}$ and James R. Gilley ${ }^{\dagger}$ \\ * Instructor and ${ }^{\dagger}$ Professor, Department of Agricultural Engineering, \\ University of Nebraska-Lincoln, Lincoln, NE 68583
}

\begin{abstract}
A simulation model was developed to estimate the effect of deficit irrigation upon crop yield. The model was designed to provide relative yield estimates for numerous combinations of irrigation system, crop growth and irrigation management parameters. A daily soil moisture balance was used to predict evaporation and transpiration from which crop yields were estimated. Gross irrigation water requirements were estimated from net irrigation requirements, irrigation efficiencies, irrigation system limitations, and effective rainfall. Crop production functions that use physically defined parameters were also developed to relate crop yields to gross irrigation requirements. The production functions worked well on a limited test compared to field data. The model and production functions are general since they depend upon readily available information or physical parameters, and can be used to evaluate irrigation management alternatives.
\end{abstract}

\section{Introduction}

Irrigation management decisions are often made without considering the effect of limited irrigation upon crop yield. When water was plentiful and energy cheap, maximum yields were generally near the optimum production level. As economic conditions change and water resources become more scarce or costly, it is imperative that economic considerations be included in water management decisions. Quantification of the effect of irrigation management upon crop production is necessary for this analysis.

Various types of models describing the effect of water stress upon plant growth and production have been developed. Detailed simulation models have been created to delineate the physiological response of plants to water stress. Unfortunately, these models are often either too complicated or too expensive to use in analyzing management decisions, and require data that may not be readily available. While crop production functions have been used in various optimization and economic studies, these functions are frequently inappropriate for management because they are often unverified or too site specific. Also, these functions are usually highly empirical and difficult to generalize. Economic solutions derived from such empirical functions are only useful for specific situations.

The objective of this paper is to present a simulation model of crop yield, which is both theoretically reasonable and computationally efficient. The model is designed to predict relative crop yield for different gross irrigation amounts and for several soils and crops using daily climatic data. Crop production func- 
tions with physically based parameters are also developed to relate the average of expected crop yield to the gross irrigation applied.

\section{Simulation Model Development and Description}

The simulation model used a daily soil moisture balance to predict the effects of moisture stress upon crop yield. Crop water use was calculated using crop coefficients and daily climatic data which are generally available for the length of record necessary to develop average crop responses to irrigation. The moisture balance was calculated by adding the net amount of water applied from irrigation and rain to the stored soil moisture and by subtracting evaporation, transpiration, and drainage losses. When simulating a sequence of years, the soil profile was assumed to be at field capacity at the start of the growing season of the first year. The initial soil moisture for subsequent years was predicted by simulating the off-season contributions to and extractions from the soil moisture balance.

Soil Properties. - The soil profile was represented by six layers to simulate evaporation, transpiration, and soil moisture redistribution. A surface layer, 2 in. $(5 \mathrm{~cm})$ thick, was used to control the evaporation rate. The second and third layers, 4 and 6 in. (10 and $15 \mathrm{~cm}$ ) thick respectively, were small to represent the soil water environment of young crops which have a shallow root system. The lower layers were each 12 in. $(30 \mathrm{~cm})$ thick.

Available water is traditionally defined as that held between field capacity and the permanent wilting point for the full rooting depth. Recent research has shown that crops, even in stress situations, do not extract water to the permanent wilting point in the lower portion of the crop root zone. The amount of water available for plant use in the root zone was predicted in a two step process. First, the effective depth of the root zone was calculated, using a linear function based upon growing degree days. The effective root zone depth varied between a minimum and maximum depth, each of which were soil and crop dependent.

Second, the amount of extractable water in the root zone was estimated using an extractable water profile developed from field research where corn was severely stressed (Figure 1). Traditionally, the permanent wilting point is defined as the moisture content corresponding to a soil moisture potential of 15 bars. This definition was adequate in the upper soil profile; however, below 30 in. $(76 \mathrm{~cm})$, the soil water was not extracted to the permanent wilting point even though the crop suffered severe water stress. Extractable water in the model was defined as the water held between field capacity and a plant extractable water limit $(9 \mathrm{~m})$ (Figure 1), which was described as:

$$
\theta_{m}=\theta_{p w p}+\left(\theta_{f c}-\theta_{p w p}\right)\left\{1-\exp \left(-2.303 z^{4.462}\right)\right]
$$

in which $\theta_{m}=$ extractable water content; $\theta_{p w p}=$ volumetric moisture content at the permanent wilting point; $\theta_{f c}=$ volumetric moisture content at field capacity; and $z=$ relative root depth (actual root depth divided by maximum root depth). The extractable water pattern was treated as a constant throughout the season for the soil profile. 


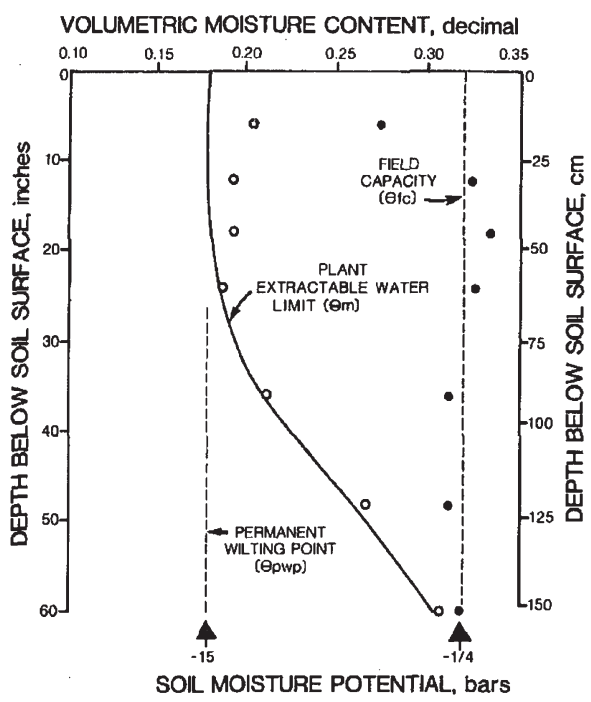

Figure I. Plant available water profile defined from measurements on Sharpsburg silty clay loam soil in spring following wet period $(\bullet)$ and dry summer where corn was severely stressed $(\circ)$.

Evapotranspiration. - Evapotranspiration (ET) was calculated based upon the reference crop evapotranspiration $\left(\mathrm{ET}_{p}\right)$, which was estimated using a locally calibrated pan coefficient and Class A Pan data, and crop coefficients. Potential evapotranspiration was separated into potential evaporation, and potential transpiration using a method similar to that of Childs and Hanks (1). The separation technique was based upon crop coefficients as defined by Jensen, et al. (8). Growing degree days prior to tasseling and days after tasseling were used to estimate canopy development and senescence. Crop coefficients $\left(K_{\mathrm{co}}\right)$ represent the amount of water used by a nonstressed crop, relative to that by a reference crop. Crop coefficients are indicative of dry soil surfaces where evaporation is at a minimal rate. When the soil surface is wetted, due to irrigation or precipitation, the evaporation rate and crop water use increase.

The method of separating potential evapotranspiration, $\mathrm{ET}_{p^{\prime}}$ into potential evaporation, $E_{p^{\prime}}$ and potential transpiration, $T_{p^{\prime}}$ in the model is illustrated in Figure 2. Prior to plant growth, $\mathrm{ET}_{p}$ consists only of evaporation potential. Once crop growth begins, the potential evaporation rate is calculated using the minimum crop coefficient, $K_{\mathrm{cmin}}$, plus the difference between the crop coefficient and the maximum crop coefficient, $K_{c m a x}$ and $\mathrm{ET}_{p}$. The evaporation potential was expressed as

$$
E_{p}=\left(K_{\text {cmax }}-K_{\text {co }}+K_{\text {cmin }}\right) \mathrm{ET}_{p}
$$

The ratio of the EP to ETp during the season is also shown in Figure 2.

Calculation of actual evaporation was similar to the procedure described by Ritchie (14). During stage one, the drying rate was assumed to be equal to the potential evaporation rate until a given volume of water evaporated from the 


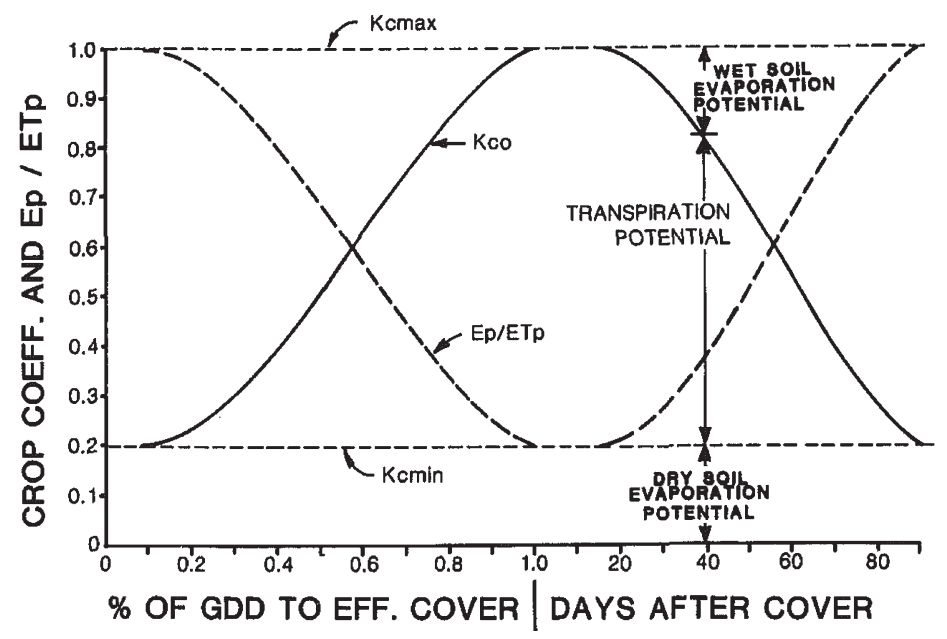

Figure 2. Generalized crop coefficient curve $\left(K_{c o}\right)$ illustrates potential evapotranspiration rate split into potential evaporation and transpiration. $K_{c m i n}$ and $K_{c m a x}$ minimum and maximum crop coefficients. $E_{p} / E T_{p}$ ratio of evaporation potential to evapotranspiration potential during season.

upper soil layer. During stage two, the evaporation rate was assumed to be inversely proportional to the square root of the elapsed time since stage two began. Evaporation ceased when the top two soil layers dropped to the air-dry soil moisture content.

When the calculated evaporation rate is less than the potential rate, some energy initially destined for evaporation was assumed to be available for transpiration. The transpiration potential was increased using a method similar to that of Childs and Hanks (1975)

$$
T_{p}=\operatorname{ET}_{p}\left\{\left[\left(K_{\mathrm{co}}-K_{\mathrm{cmin}}\right) /\left(K_{\mathrm{cmax}}-K_{\mathrm{cmin}}\right)\right]\left[K_{\mathrm{cmax}}-K_{\mathrm{cmin}}\left(E / E_{p}\right)\right]\right\}
$$

in which $E_{p}=$ potential evaporation; $E=$ actual evaporation; and $T_{p}=$ potential transpiration rate.

The transpiration rate increase is limited by the energy available, so the transpiration potential, plus the actual evaporation, is s the maximum water use rate. The maximum water use rate is the product of the reference crop evapotranspiration, $\mathrm{ET}_{p}$, and the maximum crop coefficient.

Potential transpiration is the rate a nonstressed plant uses water. When stress occurs, the transpiration rate decreases relative to the potential rate due to stomatal closure. We simulated this process indirectly using a stress factor similar to that of Hanks (4). The soil moisture stress factor depends upon the amount of water remaining in the crop root zone. When less than half of the extractable water remained, the transpiration rate was assumed to decrease. The stress factor was defined as

$$
K_{s}=1.0 ; \text { if } E_{w}>0.5 ; \quad K_{s}=E_{w} / 0.5 ; \text { if } 0.0 \leq E_{w} \leq 0.5
$$


in which $K_{s}=$ stress factor; and $E_{w}=$ fraction of extractable water remaining in the crop root zone.

The actual transpiration demand of the crop is given by

$$
T=K_{s} T_{p}
$$

in which $T=$ actual transpiration; and $T_{p}=$ potential transpiration.

The actual transpiration rate represents the amount of water to be removed from the crop root zone. In the model, water was removed from the wettest soil layer first. If the extractable water in the layer was insufficient to meet the demand, water was used from the next wettest layer. This process continued until the transpiration demand was satisfied, or until all extractable water was used. A transpiration deficit was defined as the difference between the potential transpiration and actual transpiration.

Water Application and Redistribution. - The effectiveness of rainfall must be known to predict crop water requirements. Infiltration and drainage resulting from rainfall were calculated separately in the model to predict rainfall effectiveness. Runoff was estimated using the SCS runoff curve number method (12) since only daily rainfall data were available. The fraction of the precipitation which runs off was estimated by rearranging the SCS equations as

$$
Q / P=(P \mathrm{CN}+5.08 \mathrm{CN}-508)^{2} \div\left(P^{2} \mathrm{CN}^{2}-20.32 P \mathrm{CN}^{2}+2,032 P \mathrm{CN}\right)
$$

in which $Q=$ the runoff depth, inches; $P=$ the precipitation amount, inches; and $\mathrm{CN}=$ the hydrologic curve number.

Curve numbers depend upon the rainfall history, cropping system, and soil type. The antecedent soil moisture conditions for the curve numbers were determined by the amount of rainfall and irrigation for the preceding five days. The depth of water required for each antecedent condition were different for the crop growing season and the period when no crops were planted.

The final component of the runoff model was developed for frozen soils. Precipitation which occurred while the soil was frozen was assumed to have run off. The soil was considered to freeze or thaw the first time the average weekly soil temperature at the $2 \mathrm{in}$. $(5 \mathrm{~cm})$ depth passed $32^{\circ} \mathrm{F}\left(0^{\circ} \mathrm{C}\right)$. Soil temperature was predicted from average weekly air temperature using a correlation function developed for Nebraska conditions by Neild (13).

Water applications were distributed throughout the soil profile using a piston flow analogy. Water was added to the profile by filling the upper layer to field capacity first, then the second, and so forth until the infiltrated volume was distributed. If excess infiltrated water was available after filling all soil layers to field capacity, all layers were filled to a volumetric moisture content greater than field capacity. Water in excess of field capacity was made available for crop use for one day, and then was assumed to drain.

Irrigation Systems. - Relevant characteristics of the irrigation system were incorporated into the simulation model to accurately estimate gross irrigation water requirements. The characteristics considered were the system capacity, ability of the system to apply varying amounts of water, and the irrigation efficiency. 
The model was constructed to consider both surface and center-pivot irrigation systems. Two types of application limits were considered; system limits and a management limit. The system limits represent reasonable minimum and maximum irrigation depths that can be applied by each system. For surface irrigation the smallest depth that can be applied per irrigation depends primarily upon the soil infiltration rate which can vary with soil type and time of season. The maximum and minimum depths for each type of irrigation can be defined differently for three periods of the growing season to reflect changes in soils or management during the year.

The management limit was developed for surface irrigation systems because an irrigation is often necessary before the soil profile can hold the minimum application depth. This is especially true early in the irrigation season when soils readily infiltrate water, but the crop root zone is shallow and the irrigation requirement small. Thus, for surface irrigation systems when the amount of water required exceeded the management limit, but was less than the minimum application, an irrigation equal to the minimum depth was applied.

Irrigation efficiency can have many meanings. In the model, irrigation efficiency was defined as the ratio of the depth of water that infiltrated the soil surface divided by the gross amount of water delivered to the field. A $10 \%$ loss of water due to runoff, evaporation, conveyance loss, and tailwater reuse inefficiency was assumed for surface irrigation. Thus, the maximum irrigation efficiency for surface systems was specified as $90 \%$. Other irrigation efficiencies can easily be used in the model for other types of analysis.

Two irrigation efficiencies were used for center-pivot irrigation. The average efficiency represented the expected efficiency that a farmer would use in making management decisions. The actual efficiency occurred for a given irrigation based upon climatic factors at the time of irrigation. The primary loss of water with center-pivot irrigation was assumed to be due to evaporation prior to infiltration. This evaporation process was simulated using the function of Clark and Finley (2). The evaporation loss was expressed as:

$$
L=3.32 \exp (0.11 u)
$$

in which $u=$ wind speed, miles per hour; and $L=$ loss percentage.

The wind data was adjusted to a height representative of pivots using the logarithmic profile method. Also from an analysis of hourly weather data, a Fourier series was developed to represent hourly wind speeds based upon the total wind travel for the day. Using the Fourier series, the average daily evaporation loss was calculated. A constant $10 \%$ loss from a center pivot application was included for runoff, nonuniformity, and plant interception which is not useful in reducing transpiration.

The average efficiency was calculated for each week using average daily wind speeds. It was assumed that the pivot operated continuously after the irrigation was started (i.e. that the operator did not stop the pivot during periods of high winds). The actual loss was calculated using wind data for the period that the pivot operated during the particular year simulated. Thus, the amount of water to apply was based upon average conditions, but the amount that infiltrated the soil surface was determined by the wind speed during the application process. 
Yield Models. - Two types of relative yield models were used. For corn, the yield model was based upon the reduction of crop yields due to transpiration reduction. The second type (used for grain sorghum, wheat and soybeans) was based upon the reduction of crop yield due to evapotranspiration deficits. The ET based models were used because actual field data were not available to calibrate the model, so functions reported in the literature were used.

Phenological stages of crop development were simulated using a growing degree basis. The growing season was divided into four stages: crop establishment, vegetative, reproductive, and yield formation. Soil moisture stress during the crop establishment stage was assumed to have no effect on yield reduction. Therefore, cumulative transpiration and evaporation amounts were maintained only for the last three stages.

Two transpiration models were evaluated. The first was proposed by Jensen (7) and modified by Hanks (4)

$$
Y_{r}=Y / Y_{m}=\prod_{i=1}^{3}\left(T_{i} / T_{p i}\right)^{\lambda_{i}}
$$

in which $Y_{r}=$ relative yield; $Y=$ actual yield; $Y_{m}=$ maximum attainable yield; $T_{i}$ $=$ transpiration during crop growth stage $i ; T_{p i}=$ potential transpiration during growth stage $i ; \lambda_{i}=$ yield sensitivity factor for period $i$; and $i=$ growth stages index; 1-vegetative, 2-reproduction and 3-grain formation.

Initially, unique values of $\lambda_{i}$ for the three stages were found through regression of modeled transpiration for corn to measured yields from Maurer (11). The regression resulted in values of $\lambda_{i}$ greater than 2.0 for the vegetative stage, indicating that transpiration reductions were most critical during that stage. This is contrary to what is expected. The sensitivity factors of 0.4 were also tested for all three stages similar to Hanks (4) and Stewart, et al. (16). The model using values of 0.4 for all sensitivity factors showed no advantage over a linear model of yield as a function of transpiration. The linear model was developed from the measured yield data and simulated relative transpiration as

$$
Y_{r}=Y / Y_{m}=1.452\left(T / T_{m}\right)-0.452
$$

in which $T=$ total seasonal transpiration; and $T_{m}=$ total seasonal transpiration potential.

Table I. Yield Coefficients for Grain Sorghum, Soybean, and Hard Red Winter Wheat

\begin{tabular}{lcl}
\hline $\begin{array}{c}\text { Crop } \\
(1)\end{array}$ & $\begin{array}{c}\text { Slope }(b) \\
(2)\end{array}$ & $\begin{array}{l}\text { Source } \\
(3)\end{array}$ \\
\hline Sorghum & \multicolumn{1}{c}{ (1) } & Garrity (4) \\
Soybeans & 1.09 & Manam (10) \\
Wheat & 1.40 & Doorenbos and Kasam (3) \\
\hline
\end{tabular}




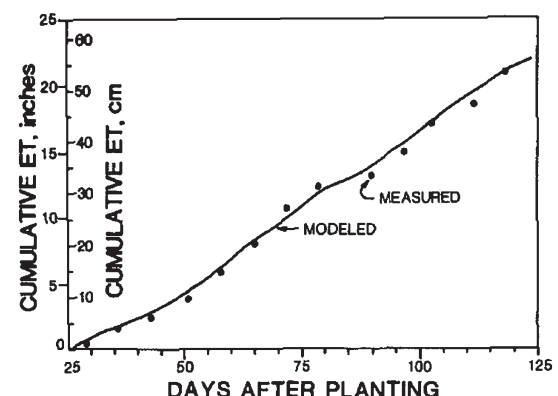

Figure 3. Comparison of simulated and measured evapotranspiration (ET) during season which corn was watered for maximum yield.

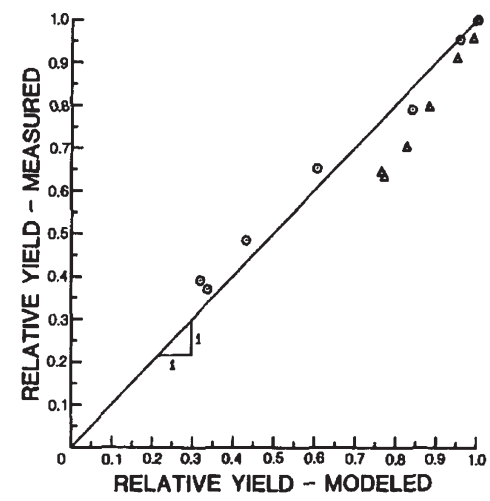

Figure 4. Comparison of measured and modeled corn yield predictions for two irrigation stress plots for stress: (a) only during grain formation stage $(\Delta)$; and (b) during reproductive and grain formation stages $(\circ)$.

The yield model developed for grain sorghum, wheat, and soybeans was a linear yield-ET model

$$
Y_{r}=Y / Y_{m}=(1-b)+b\left(\mathrm{ET} \mathrm{ET}_{m}\right)
$$

in which $\mathrm{ET}$ = seasonal crop evapotranspiration; $\mathrm{ET}_{m}=$ seasonal evapotranspiration for a well watered crop for which maximum yields are achieved; and $b=$ empirical yield model coefficient.

Coefficients for these models are summarized in Table 1 for the three crops. The yield-ET model requires estimation of the evapotranspiration of a crop which is not stressed. It was assumed that water use was not reduced when less than $50 \%$ of the extractable water was depleted.

Evapotranspiration during the season was simulated with the model and compared to experimental results from Maurer (11). Field data were measured using a soil moisture balance on an irrigation treatment which received enough water to replace crop ET on a weekly basis. Using the soil properties from the site, the model predicted the seasonal ET pattern well (Figure 3). Yield predictions from the model were compared to results from the two stress treatments from Maurer. One received adequate water until the beginning of the grain formation stage, and the second was adequately watered during the vegetative stage and then stressed during the reproductive and grain formation stages. Although the model does not predict exactly, it compared favorably to the general trend of the field results (Figure 4). The maximum error in relative yield was about $10 \%$.

\section{Crop Production Function}

Development of Mathematical Relationships. - Simulation models are useful in evaluating crop response to water for various combinations of soils, irri- 
gation systems, and years. Development of irrigation management strategies requires numerous simulations, especially for variable climates where sporadic rainfall occurs. Using the technique described herein, the crop response to irrigation can be incorporated into a functional relationship that depends upon physical parameters that can be readily defined. Simulation results can then be generalized to analyze situations and locations without extensive additional simulation.

Two terms were defined to reduce the annual variation of simulation results and analyze the expected response of a crop to irrigation. One term is the yield response ratio and was defined as

$$
\mathrm{YRR}=\left(Y-Y_{d}\right) \div\left(Y_{m}-Y_{d}\right)
$$

in which $\mathrm{YRR}=$ yield response ratio; $Y_{m}=$ maximum yield; $Y_{d}=$ dryland yield; and $Y=$ yield at some irrigation level. The yield response ratio represents the fraction of the maximum yield increase from irrigation that is realized with deficit irrigation. The yield response ratio can also be expressed using the relative yield

$\mathrm{YRR}=\left(Y_{r}-Y_{r_{d}}\right)\left(1-Y_{r_{d}}\right)$

in which $Y_{r}=$ the relative yield at some irrigation level; and $Y_{r_{d}}=$ the relative yield for dryland conditions.

Additionally, the amount of irrigation was normalized by defining the relative irrigation as

$$
I_{r}=I / I_{m}
$$

in which $I_{r}=$ the relative irrigation; $I=$ the irrigation level; and $I_{m}=$ the amount of irrigation necessary to give maximum yield for the season and system simulated.

The yield response ratio and relative irrigation terms help separate the seasonal variation of crop yield resulting from irrigation into three components. Two components of the variation are due to the variability of the dryland yield and maximum irrigation requirement. The other component is the variation of the crop response to water stress. Gilley et al. (5) simulated two types of irrigation management strategies: one where stress was uniform over the entire season, and another where stress was alleviated during the middle portion of the growing season. The yield response ratio for a given strategy was nearly the same for a given relative irrigation amount from year to year. These results suggest that crops respond similarly to a specific deficit irrigation strategy. Functions of the yield reduction ratio versus the relative irrigation amount were used to represent that response.

Various relationships for the yield response ratio, as a function of the relative irrigation, can be used. Using the designation of $f\left(I_{r}\right)$ as a general yield response ratio function, and by rewriting Equation 12, the expression for the relative yield becomes

$$
Y_{r}=Y_{r_{d}}+\left[\left(1-Y_{r_{d}}\right) f\left(I_{r}\right)\right]
$$


In terms of absolute yield the production function becomes

$$
Y=Y_{d}+\left[\left(Y_{m}-Y_{d}\right) f\left(I_{r}\right)\right]
$$

If a linear evapotranspiration-yield model is used to predict relative yield, the following relationship can be derived

$$
\mathrm{ET}=\mathrm{ET}_{d}+\left[\left(\mathrm{ET}_{m}-\mathrm{ET}_{d}\right) f\left(I_{r}\right)\right]
$$

Taking the derivative of Equation 16 with respect to the amount of irrigation gives

$$
\partial \mathrm{ET} / \partial I=\left(\mathrm{ET}_{m}-\mathrm{ET}_{d}\right) \partial f / \partial I
$$

Physical requirements and the preceding definitions condition the mathematical relationship chosen for the yield response ratio. First, when the maximum irrigation requirement is applied $I_{r}=1$ and $\mathrm{ET}=\mathrm{ET}_{m^{\prime}}$ thus using Equation 16

$$
f\left(I_{r}=1\right)=1.0
$$

When no irrigation is applied $\left(I_{r}=0\right)$, ET equals the amount of evapotranspiration $\left(\mathrm{ET}_{d}\right)$ needed to produce the dryland yield. Using Equation 16 the second condition on $f\left(I_{r}\right)$

$$
f\left(I_{r}=0\right)=0
$$

Finally, Stewart and Hagan (15) indicated that $\partial \mathrm{ET} / \partial \mathrm{I}$ often equals 1 when evaluated at $I=0$. This implies that when a negligibly small amount of irrigation water is applied to a field, it can be done in such a way that all of the water is consumed in either evaporation or transpiration. This assumption seems plausible with modern irrigation technology and when combined with Equation 17 requires that

$$
(\partial f / \partial I)_{I=0}=1 /(\mathrm{ET} m-\mathrm{ET} d)
$$

Hexem and Heady (7) present several types of crop production functions relating crop yields to the amount of irrigation water applied. The yield response ratio functions, and the nomenclature of Hexem and Heady (7) for three crop production functions are

$$
\begin{aligned}
& \text { Quadratic: } f\left(I_{r}\right)=a_{1} I_{r}+a_{2} I_{r}^{2} \\
& \text { Cobb-Douglas: } f\left(I_{r}\right)=m-\left(1-I_{r}\right)^{n} \\
& \text { Mitscherlich-Spillman: } f\left(I_{r}\right)=\alpha\left[1-\exp \left(-\beta I_{r}\right)\right]
\end{aligned}
$$

The constants of these equations can all be related to physical parameters using the conditions specified in Equations 18, 19, and 20. The resulting expressions for the constants are given in Appendix I.

All the functional relationships use the same dimensionless parameter; i.e., the portion of the maximum irrigation that goes to ET. Similar relationships would occur if the linear transpiration model were used, rather than the evapotranspiration model.

Using the yield response ratio, a linear yield-ET model, and the conditions specified in Equations 18-20, commonly used crop production functions can be 


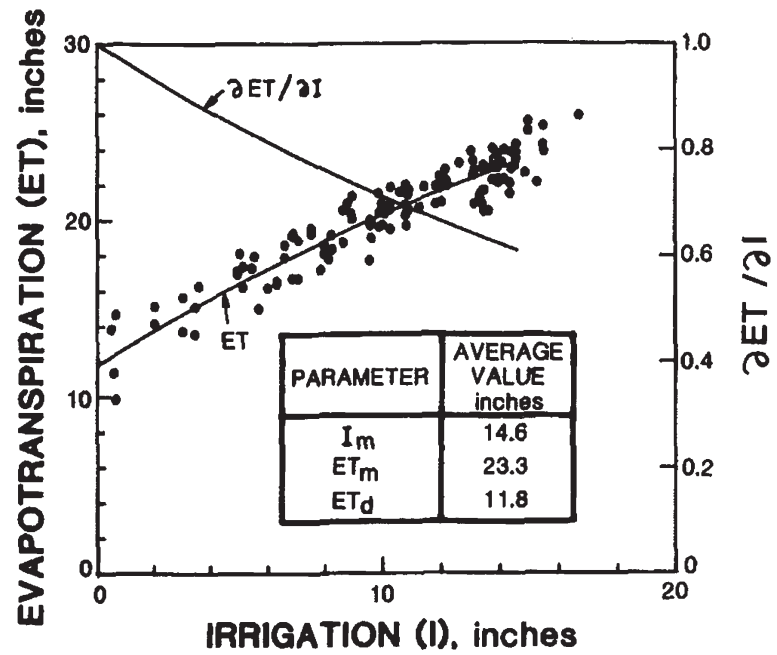

Figure 5. Comparison of measured evapotranspiration to predictions using Mitscherlich-Spillman type yield response ratio.

developed from physical parameters. Simulation is only required to define $\mathrm{ET}_{d}$ , $\mathrm{ET}_{m}$, and $I_{m}$ for the irrigation strategy used. The maximum yield is necessary to convert relative yields to actual yield and is usually defined by other means. The dryland yield is defined once $Y_{m^{\prime}} \mathrm{ET}_{m}$, and $\mathrm{ET}_{d}$ are found. The advantage of this procedure over pure simulation methods is the reduced amount of simulation needed to describe the yield resulting from deficit irrigation.

It may appear that only one crop-production function is possible for a given year since $\mathrm{ET}_{m}$ is associated with $Y_{m}$. The key is that different irrigation strategies, soils, and systems will require different amounts of irrigation to produce the maximum ET and yield. For example, suppose one irrigation strategy is to refill the crop root zone every third day, versus a policy of maintaining the soil moisture depletion in a range where ET is not reduced, but room is left in the root zone to store rainfall. The second strategy will most likely require less irrigation to produce the maximum yield if rain does occur.

Evaluation of Yield Response Ratio.-Three fundamental assumptions were made in this development. First, the linear yield-ET or yield- transpiration model was used. Clearly, if this relationship is inadequate the developed expressions do not hold. Second, it was assumed that the yield response ratio can describe a crop's response to irrigation for a particular irrigation strategy. And, third, it was assumed that at negligibly small irrigation levels all of the water applied as irrigation goes toward ET.

The third assumption can be evaluated by comparing Equation 18 to field data. Data on evapotranspiration versus irrigation from water balance experiments by Maurer (11) were used to produce Figure 5. The equation defined by the physical parameters appears to work reasonably well in describing the variation of ET with irrigation. The data represent results from six irrigation treatments, of three to four replications, where varying amounts of water were ap- 


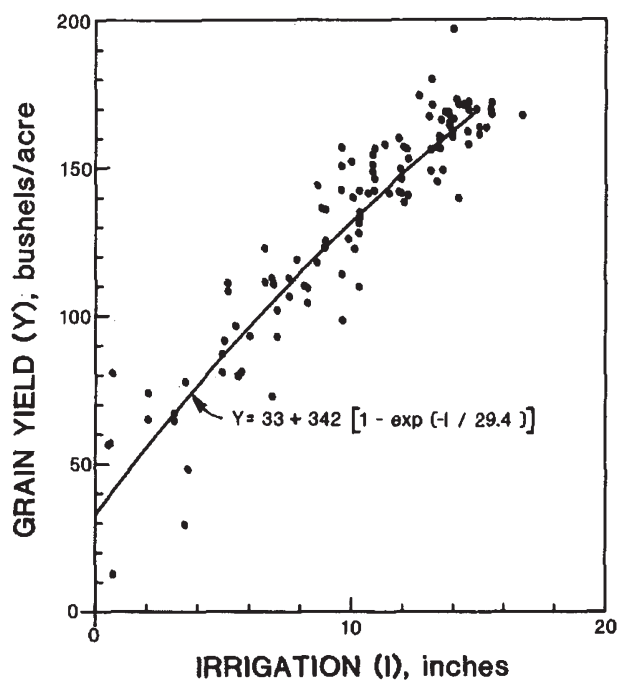

Figure 6. Comparison of measured corn yields to predicted yields using Mitscherlich-Spillman form of yield response ratio.

plied during the vegetative, reproductive, and grain fill stages. Thus, varying amounts of stress occurred during each stage, so the results represent a broad range of irrigation regimes. Yet the data tend to be reasonably well described by Equation 16.

The fraction of the irrigation used in ET is also shown in Figure 5. This fraction is simply the derivative of the ET-irrigation curve. More than $60 \%$ of the water for irrigation was used for ET at all irrigation levels; however, even with carefully managed irrigation, as much as $40 \%$ of the last unit of water applied may be unused when irrigating for maximum yields. The unused water may not be wasted, as it can be stored in the crop root zone for future use. However, if offseason rainfall causes drainage, the water is essentially lost.

The second assumption, regarding the use of the yield response ratio, can also be evaluated by comparing measured and predicted yields (Figure 6). The average maximum grain yield in the experiments by Maurer (11) of 167 bushels/acre $(10,500 \mathrm{~kg} / \mathrm{ha})$ was used with the production function. Although there is scatter to the data, the physically defined yield model appears to describe the results as well as a regression model might.

The Mitscherlich-Spillman equation was used in Figure 6. Both the quadratic, or Cobb-Douglas, showed very similar results. Grain yield predictions were not severely affected by the function used. However, the Cobb-Douglas equation is substantially different in terms of $\partial \mathrm{ET} / \partial \mathrm{I}$ (Figure 7). The last unit of irrigation provides no increase in ET at the maximum irrigation level using this form of the Cobb-Douglas equation. Although this result does not materially affect the yield estimate, it may influence the optimal amount of irrigation to apply because the yield increase per unit of water is much below that for the other two equations when irrigation is applied near the maximum requirement. 


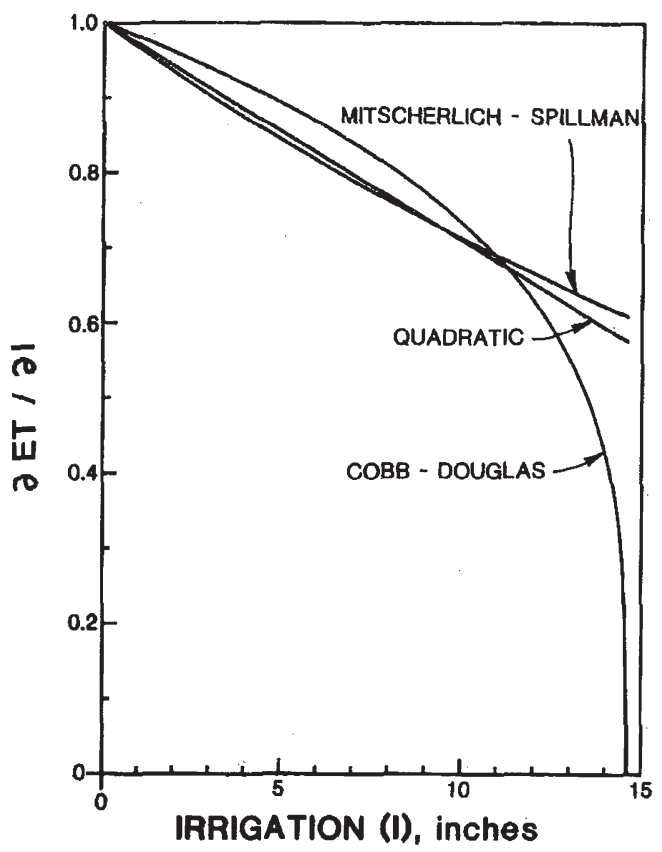

Figure 7. Comparison of derivative of evapotranspiration (ET) from corn with respect to irrigation for three yield response ratio equations.

\section{Summary and Conclusions}

A model has been presented which can be used to predict relative yield reductions due to deficit irrigation. The hydrology of the irrigated field and yield models from recent research were incorporated to simulate the effect of evapotranspiration and transpiration deficits upon crop yield. The model is general enough to allow other crop yield-ET functions to be used, is compatible with generally available data, and yet simple enough to simulate a large number of combinations inexpensively.

A method was also presented to develop physically based crop production functions which relate grain yield to the amount of irrigation water applied. The crucial parameter is the portion of the maximum irrigation amount that is used for evapotranspiration or transpiration. The resulting expressions were compared to field data and appear reasonable.

A method of using simulation models to develop general production functions was developed in the paper. The resulting functions use parameters that have a physical meaning and can be defined from simulation results or past experience. Thus, the resulting functions are applicable to a wider range of conditions than typical production with coefficients derived from regression. The functions will also be useful in evaluating economic and management decisions using ratios of physically based parameters instead of regression coefficients. This will ultimately provide more general information for making management decisions. 


\section{Acknowledgments}

Contributed from the Nebraska Agricultural Experiment Station, Lincoln, Nebraska. Published with the approval of the Director as Paper No. 7267, Journal Series, Nebraska Agricultural Experiment station. The writers would like to acknowledge the suggestions furnished by Dr. R. J. Hanks via personal communication. His insights were gratefully received and accepted.

\section{Appendix I. Expressions Relating Yield Response Ratio Constants to Physical Parameters}

$\begin{array}{ll}\text { Quadratic Form (Equation 23) } & a_{1}=I_{m} /\left(\mathrm{ET}_{m}-\mathrm{ET}_{d}\right) \\ & a_{2}=1-a_{1} \\ \text { Cobb-Douglas Form (Equation 24) } & m=1 \\ & n=I_{m} /\left(\mathrm{ET}_{m}-\mathrm{ET}_{d}\right) \\ \text { Mitscherlich-Spillman Form (Equation 25) } & \beta /[1-\exp (-\beta)]=I_{m} /\left(\mathrm{ET}_{m}-\mathrm{ET}_{d}\right) \\ & \alpha=1 /[1-\exp (-\beta)] .\end{array}$

\section{Appendix II. References}

1. Childs, S. W., and Hanks, R. J., "Model of Soil Salinity Effects on Crop Growth," Soil Science Society of American Journal, Vol. 39, No. 4, July, 1975, pp. 617-622.

2. Clark, R. N., and Finley, W. W., "Sprinkler Evaporation Losses in the Southern Plains," presented at the Dec. 15-18, 1975, Winter Meeting of the American Society of Agricultural Engineers, held at Chicago, 111., (Paper No. 75- 2573).

3. Doorenbos, J., and Kassam, A. H., "Yield Response to Water," Food and Agriculture Organization of the United Nations, Irrigation and Drainage Paper 33, Rome, 1979.

4. Garrity, D. P., "Moisture Deficits and Grain Sorghum Performance, Limited Irrigation Strategies, Evapotranspiration Relationships, Stress Conditioning, and Physiological Responses," thesis presented to the University of Nebraska at Lincoln, Neb., in 1980, in partial fulfillment of the requirements for the degree of Doctor of Philosophy.

5. Gilley, J. R., Martin, D. L., and Splinter, W. E., "Application of a Simulation Model of Corn Growth to Irrigation Management Decisions," Operations Research in Agriculture and Water Resources, D. Yaron and C. Topiero, eds., North Holland Pub. Co., New York, N.Y., 1980, pp. 485-500.

6. Hanks, R. J., "Model for Predicting Plant Yield as Influenced by Water Use," Agronomy Journal, Vol. 66, No. 5, Oct., 1974, pp. 660-664.

7. Hexem, R. W., and Heady, E. O., "Water Production Functions for Irrigated Agriculture," The Iowa State University Press, Ames, Iowa, 1978.

8. Jensen, M. E., Wright, J. L., and Pratt, B. J., "Estimating Soil Moisture Depletion From Climate, Crop and Soil Data," Transactions, American Society of Agricultural Engineers, Vol. 14, No. 5, Oct., 1971, pp. 954-959.

9. Jensen, M. E., "Water Consumption by Agricultural Plants," Water Deficits and Plant Growth, T. T. Kozlowski, ed., Vol. 2, Academic Press, New York, N.Y., 1968, pp. 1-22.

10. Manam, R., "Physiological and Agronomic Studies in Soil-Plant-Water Relations of Soybeans," thesis presented to Kansas State University at Manhattan, Kans., in 1974, in partial fulfillment of the requirements for the degree of Doctor of Philosophy. 
11. Maurer, R. E., "Effect of Timing and Amount of Irrigation and Drought Stress Conditioning in Corn (Zea mays L.)," thesis presented to the University of Nebraska, at Lincoln, Neb., in 1981, in partial fulfillment of the requirements for the degree of Doctor of Philosophy.

12. National Engineering Handbook, Section 4, United States Department of Agriculture, Soil Conservation Service, United States Government Printing Office, Washington, D.C., 1956.

13. Neild, R. E., "Growing Season Air-Soil Temperature Relationships at Lincoln, Nebraska," Research Bulletin 242, Nebraska Agricultural Experiment Station, University of Nebraska, Lincoln, Neb., 1971.

14. Ritchie, J. T., "Model for Predicting Evaporation from a Row Crop with Incomplete Cover," Water Resources Research, Vol. 89, No. 5, Oct., 1972, pp. 1204-1213.

15. Steward, J. I., and Hagan, R. M., "Functions to Predict Effects of Crop Water Deficits," Journal of Irrigation and Drainage, ASCE, Vol. 99, No. IR4, Dec, 1973, pp. 421-439.

16. Stewart, J. I., et al., "Optimizing Crop Production Through Control of Water and Salinity Levels in the Soil," Utah Water Research Laboratory, PRWG 1511, Utah State University, Logan, Utah, 1977.

\section{Appendix III. Notation}

The following symbols are used in this paper:

$a_{1}, a_{2}=$ constants used in quadratic production function

$b \quad=$ empirical constant in yield-ET or yield-T models

$\mathrm{CN}=$ curve number for SCS runoff method

$E \quad=$ actual amount of evaporation from soil

$E_{p} \quad=$ potential amount of evaporation from soil if ample water is available

$E_{w} \quad=$ fraction of extractable water in crop root zone

ET = seasonal evapotranspiration

$\mathrm{ET}_{d} \quad=$ seasonal evapotranspiration for dryland conditions

$\mathrm{ET}_{m} \quad=$ seasonal evapotranspiration for crop never suffering water stress

$\mathrm{ET}_{p} \quad=$ daily potential evapotranspiration for fully developed crop canopy

$f\left(I_{r}\right) \quad=$ functional relationships for yield response ratio

$i \quad=$ growth stage index

I = seasonal amount of irrigation

$I_{m} \quad=$ seasonal amount of irrigation for crop never suffering water stress

$I_{r} \quad=$ relative seasonal irrigation

$K_{\mathrm{co}} \quad=$ crop coefficient

$K_{\mathrm{cmax}}=$ maximum value of crop coefficient

$K_{\mathrm{cmin}}=$ minimum value of crop coefficient

$K_{s} \quad=$ stress factor to reduce transpiration when less than half of extractable water remains in crop root zone

$L \quad=$ percent of sprinkler application lost due to evaporation

$m, n=$ constants used in Cobb-Douglas production function 


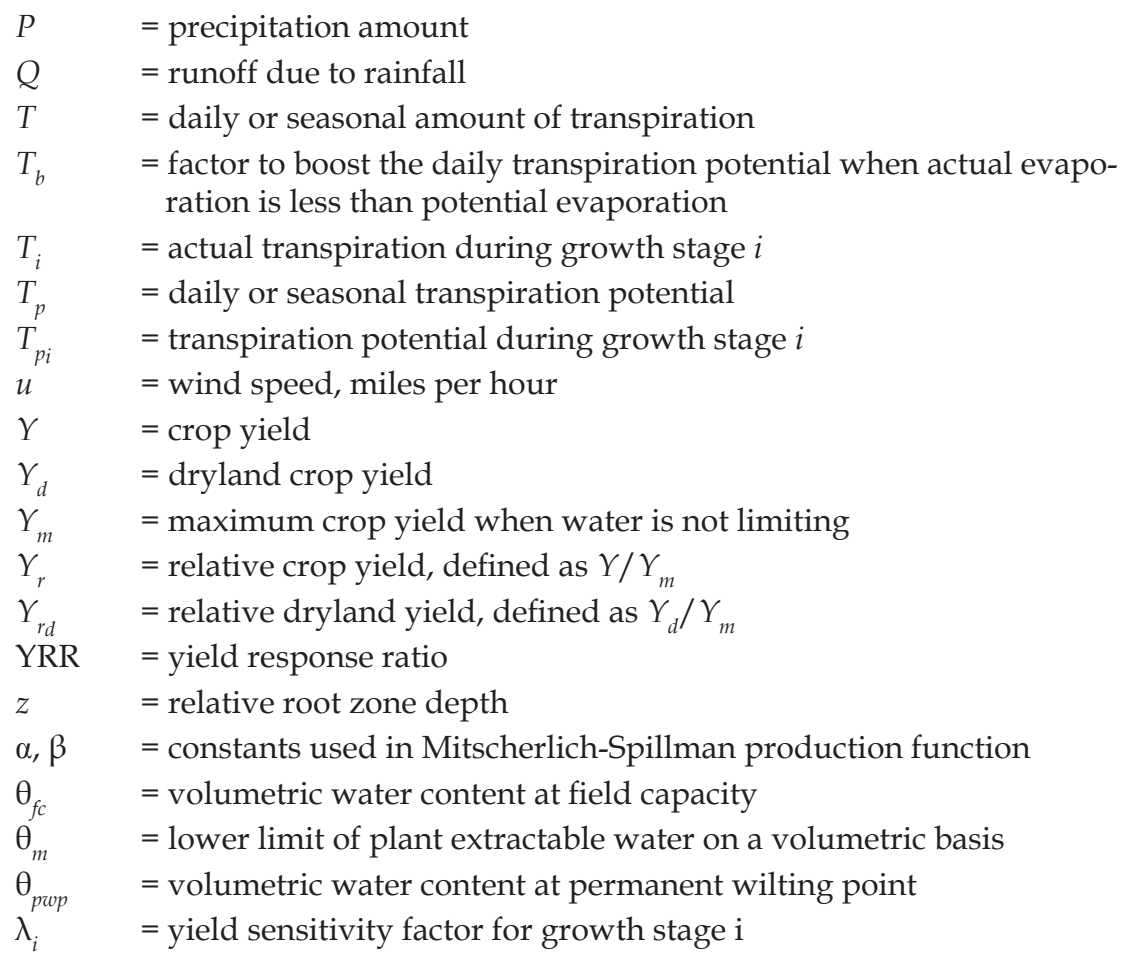

